\title{
Energy-Water-Environment Nexus and the Transition Towards a Circular Economy: The Case of Qatar
}

\author{
Abdul-Jalil Ibrahim $^{1}$ (D) Nasim Shah Shirazi ${ }^{1}$ \\ Received: 19 October 2020 / Accepted: 23 March 2021 / Published online: 3 April 2021 \\ (C) The Author(s) 2021
}

\begin{abstract}
Background Qatar's per capita consumption of both energy and water is among the highest in the world. Documentation of methods to reduce energy and water use and its impact on the environment is crucial. A circular economy (CE) ensures that economic growth must not necessarily lead to more resource consumption.

Materials and methods This study aims to discuss the CE approach with a focus on understanding the interdependencies between energy and water and their impact on the environment. The study explores the energy-water-environment nexus and how Qatar can leverage this to transition to a CE. The policy landscape and strategies related to energy and water use sectors are presented, addressing efficiencies and substitutes from a circular economic viewpoint.

Results The findings show that electricity and mobility sectors(energy perspective of the $\mathrm{CE}$ ) and agriculture and water supply system (water perspective of the CE) of the Qatari economy provide an opportunity for regeneration, virtualising, exchanging, optimising, sharing and closing loops to achieve CE growth.

Conclusions The nexus between the mobility, electricity, agriculture and water supply system needs consideration for optimal policy outcome for the CE in Qatar. The study recommends a need to embark on public awareness on moving away from linear economic to the circular economic paradigm and developing a comprehensive policy on Qatar's circular economic approach that consolidates the Qatar National Vision 2030 and the National Development Strategy 2018-2022 to provide policy clarity and communication towards $\mathrm{CE}$.
\end{abstract}

Keywords Circular economy · Energy $\cdot$ Water $\cdot$ Environment

Abdul-Jalil Ibrahim abdibrahim@hbku.edu.qa

Nasim Shah Shirazi nshirazi@hbku.edu.qa

1 Islamic Finance Department, Hamad Bin Khalifa University, P.O. Box 34110, Doha, Qatar 


\section{Introduction}

The global consumption of energy and water resources has significantly increased in recent years [1]. Water use affects energy, food, industrial output, and environment quality [2]. About $15 \%$ of global water is used for energy, and $8 \%$ of global energy is used for water production as energy is expended to treat and distribute freshwater. In return, water is used for cooling thermal power plants [3-6]. Activities such as electricity generation, farming, petroleum processing, and the like require water [7]. Globally, water and energy demand has increased over the years due to the growth of economies and population jump. This development has increased human vulnerability to the climate change impact [8]. The link between water and energy use and the environmental outcome is that production and consumption of water and energy produce carbon emissions, which pollute the environment and hampers ecological sustainability.

According to the World Resource Institute, Qatar is the most water-stressed country globally in 2019 [9]. Water scarcity in Qatar is caused by the climatic condition of low precipitation and groundwater. The annual per capita water from rainfall and groundwater is $71 \mathrm{~m}^{3}$, which can only meet $7 \%$ of water demand per annum [10]. Qatar's situation is critical as a rainfall water source is below the average in the Arab region of $850 \mathrm{~m}^{3}$ and $7000 \mathrm{~m}^{3}$ of the world [11]. Consequently, almost 75\% of Qatar's municipal water supply is being produced by desalination. This comes with high energy consumption, thus creating approximately 4.66 million tons of $\mathrm{CO} 2$ into the environment with its attendant adverse effects on human health and the environment [12]. The agriculture sector remains the largest consuming segment of water supply, representing about $41 \%$ of total consumption in 2019 . This is followed by the household sector of about $35 \%$ in the same year (see Fig. 1).

In terms of water recycling, Ministry of Development Planning and Statistics (now Planning and Statistics Authority) data shows that there has been an increased urban wastewater treatment in Qatar. As of 2019, almost all of the urban wastewater generated was treated. The agriculture sector is the leading consumer of recycled water, accounting for $81 \%$. The remaining wastewater is injected back to the aquifers, to irrigate public green spaces, and into lagoons [13]. Despite Qatar's limited water resources, the country remains the highest water per capita consuming state in the world [14]. The high water consumption is driven by increasing population, urbanisation, and industrial development [15]. Prioritising CE practices in water policy will provide a vital policy perspective and tool for sustainable water supply and use in Qatar. When it comes to energy resources, Qatar has an abundance of it, and this has reduced the financial burden on relying on almost $100 \%$ desalination for potable water on one hand.

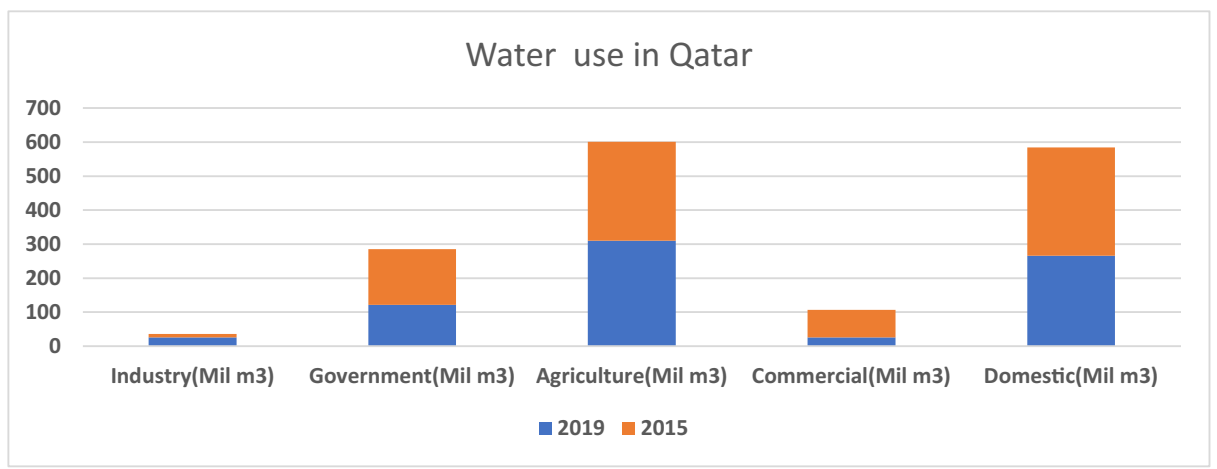

Fig. 1 Sectoral water use in Qatar (Source: [13]) 
On the other hand, this comes at a substantial environmental cost due to the greenhouse gas emissions from natural gas-powered thermal plants [12]. The energy sector is the leading cause of air pollution in Qatar as it accounts for about $96 \%$ of greenhouse gas emissions in 2012 [16]. This is occasioned by the fact that oil and gas are the dominant sectors of the energy mix used in electricity generation, heat production, and transportation. Even though natural gas is cleaner than other fossil fuel sources, it still contributes to high environmental pollution because of the high consumption [17]. Comparatively, Qatar was the second-highest consumer of electricity among the GCC countries in 2009 as its consumption was almost five times of the world's average of $2684 \mathrm{kWh}$ per capita [18]. The high energy consumption has led to the net increase in Qatar's energy intensity between 2009 and 2015. Ideally, energy intensity should be decreasing year on year when a country is becoming energy efficient. Decreasing energy intensity means that more economic output is generated with less energy, as seen in the USA, UK, Turkey, China, and the world average, as presented in Fig. 2.

Waste reduction, keeping products and material at the highest value, and extracting all possible by-products from resources may reduce energy and water consumption. This approach can be operationalised by applying the CE principle [19]. Society and businesses are moving toward CE. This concept has emerged in response to the drawbacks of the conventional "takemake-consume and dispose of" model of growth [20]. Underpinning the CE is the principle of decoupling economic growth from finite resources consumption, which requires a transition to renewable resources and driving value from waste out of the system [21]. Energy and water play an essential role in the shift towards a $\mathrm{CE}$ as efficiencies gained from the energy-water nexus will positively impact the environment. For instance, energy systems that are resilient, renewable, localised, and distributed efficiently will positively impact the environment [22].

Qatar has witnessed unprecedented industrial development over the past 2 decades [23]. The substantial improvements in the economic sectors, the vast population growth, and the increase in production and consumption of carbon-linked resources have renewed the concern about the relationship between economic growth and its linkage to Qatar's environmental quality [24, 25]. Qatar National Vision 2030 (QNV2030) captures the CE targets in pillars three and four on sustainable development and environmental development, respectively. The commissioning of the carbon capture and storage project to sequester 5 million tonnes of carbon from liquified natural gas (LNG) facilities by 2025 is a clear manifestation of Qatar authorities' desire to transition to a CE [26]. In the context of Qatar's climatic conditions, high energy and water consumption, and the efforts towards a CE, the main question of this study is to find out if the nexus between energy, water, and the environment provides a policy tool in

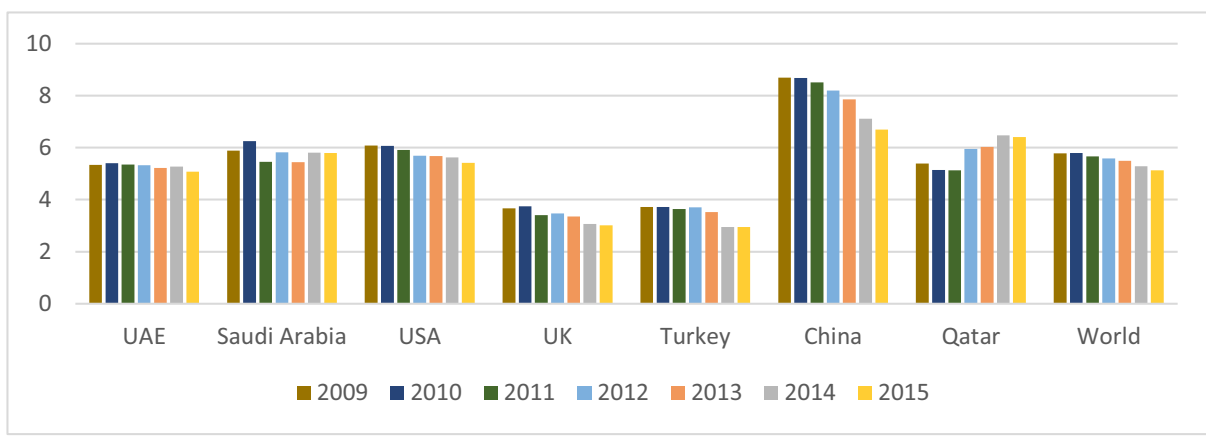

Fig. 2 Energy intensity across countries and the world (Source: [17]) 
developing a CE transition plan in the case of Qatar. It is imperative to understand the interdependence between energy and water to formulate policies and implement more efficient and effective policies to conserve more resources [27]. There is no reported study to the best of our knowledge on this topic in the context of Qatar, a small country with high water and energy consumption per capita.

\section{A Global Review of CE Policy Landscape}

Many countries have embraced the CE approach to economic growth and development. This has manifested from both policy and business development perspectives with the view that it is seen as a way to achieve sustainable environmental and economic development [28-30]. The traditional economic growth model described as an extract-produce-use-dump material and energy flow model of the modern economic system is seen as environmentally unsustainable [31]. Consequently, CE is promoted as a model that will spur the economic system with an alternative flow model, one that is cyclical and regenerative when it comes to resource use [28], [32, 33].

$\mathrm{CE}$ is far broader than traditional recycling. The practical policy and business advocacy orientated CE approach emphasise product, component, and material reuse, remanufacturing, refurbishment, repair, cascading, and upgrading. The potential of sustainable energy sources such as solar, wind, biomass, and waste-derived energy utilisation underpinned by the cradle-to-cradle life cycle approach is also prioritised in a CE [32] [34-36]. As an emerging concept or approach, there is no consensus in the definition of CE. The European Commission's definition, couched in the 4Rs, describes CE to reduce, reuse, recycle, and recover (see Table 1).

The concept of CE has been around for many decades. However, it has been popularised in recent years owing to the advocacy by some non-governmental organisations such as the Ellen MacArthur Foundation, which has conducted extensive studies on the topic [33]. According to the 73rd UN General assembly, the CE holds particular promise for achieving multiple Sustainable Development Goals (SDGs), including SDGs 8 on economic growth, 6 on clean water and sanitation, and 7 on affordable and clean energy.

The CE's enormous benefit has motivated many countries to formulate policies and strategies toward transiting from the linear economy to CE. The European Union has been at the forefront of the CE transition. The Lisbon Treaty outlines the guiding principles of EU environmental protection policy and its objectives, including a guide to ensure the "prudent and rational utilisation of resources". This provides the legal basis for the EU's action in the

Table 1 CE definition according to the European Commission (Source: [37])

\begin{tabular}{ll}
\hline $\begin{array}{l}\text { CE } \\
\text { Perspective }\end{array}$ & Explanation \\
\hline Reduce & $\begin{array}{l}\text { Discussion around reducing, rethinking, redesigning } \\
\text { (to prolong products lifespan), minimisation and prevention of resource use } \\
\text { Discussion around reusing (excluding waste), closing the loop, cycling, repairing, and/or } \\
\text { refurbishing resources }\end{array}$ \\
$\begin{array}{l}\text { Recycle } \\
\text { Recover }\end{array}$ & $\begin{array}{l}\text { Discussion around remanufacturing, recycling, closing the loop, recycling, and/or reuse of waste? } \\
\end{array}$
\end{tabular}


area of sustainable resource use and the CE [38]. The CE package was adopted in 2014, which was entitled "Towards a CE: a zero-waste program for Europe", which established a common and coherent EU framework to promote the $\mathrm{CE}$ targeting recycling, job creation, new business models eco-design, and industrial symbiosis, and reducing greenhouse emissions [39]. This policy was replaced by a new one titled "Closing the Loop - An EU Action Plan for the CE", which appears to put much emphasis on eco-innovation to cover the whole process from design to disposal and recovery/recycling [30]. The new measures support the eco-design directive to achieving reparability, durability, and recyclability in product requirements. The legislative proposal targets $65 \%$ recycling for municipal waste by $2030,75 \%$ recycling of package waste by 2030, and limiting landfill use for waste to $10 \%$.

The House of Commons report in the UK recommended adopting the CE using government incentives and catalyst to signal consumers and producers. Some of the interventions suggested included taxation reforms, regulating producers' responsibility by rewarding reuse, and making funds available to organisations that promote recovery of materials. Other proposed interventions include using government procurement power to compel organisations not to supply non-recyclable materials when recyclable one is available [40]. It is essential to mention that the government rejected some of the recommendations and only implemented the recyclability and the producer responsibility schemes in the economy's emerging sectors [41].

In Asia, China is providing a leading role in CE transition by enacting a CE Promotion Law of the People's Republic of China. The Law's essence is to provide a legal and policy framework for promoting CE, improving resource efficiency and protecting and improving the environment in a sustainable way [42]. China's CE policy approach is to go beyond environmental management and recycling to holistically deal with the latest development paradigm of closing the loops of material flow within the entire value chain of extraction and production. Zhu [43] outlines some of the activities undertaken by stakeholders in China towards CE adoption, including working with some strategic enterprises at the micro-level, establishing circular industrial parks at the meso level, and selecting some cities and regions to champion the pioneering work of $\mathrm{CE}$ transition at the national level. To summarise, China's current development effort is trying to synch with the CE, including massive investments in the shift to renewable energy, the rapid development of digital technologies, and a boom in asset-sharing platforms [44]. Despite this effort, many challenges exist that may undermine the CE's complete transition, and among these are microeconomic factors, market failures, regulatory barriers, and societal customs.

Japan is another country that has pursued policies geared toward adopting CE, which is primarily driven by the resource-scarcity in the country as it seeks to optimise resource use [42]. The government passed the Law on promoting the efficient use of resources in 2000 [45]. This was followed by establishing the fundamental plan for establishing a sound material-cycle society. The plan provides for the clarification and blueprint for reforming society's lifestyles based on mass production, consumption, and disposal. The Law, on the other hand, establishes a general guide by focussing on waste management and effective utilisation of resources, including extended producer responsibility, as well as legislation focused on specific products including packaging, home appliances, food, construction materials, and vehicles [46]. The country developed an indicator for measuring progress towards a CE by the rate of recycled goods, disposal, and material productivity with policies targeting raising productivity and recycling and minimising disposal in the long run [47].

There is no comprehensive policy on CE in the Gulf Coorporating Countries (GCC) despite the enormous potential within the countries in the region. According to a World Government 
Summit report [48], GCC countries can save almost $\$ 138$ billion by 2030 if they adopt a circular economic model. This corresponds to nearly $1 \%$ of the region's cumulative GDP between 2020 and 2030. Despite the lack of CE policies, the GCC countries have, in one way or the other, started to explore sustainable solutions in their development policies. Some of them have captured renewable energy targets, addressing unmitigated consumption and waste management in their national visions and strategic targets [48]. For instance, QNV2030 outlines how the country can achieve sustainable economic and environmental development [49]. United Arab Emirates Vision 2021 includes ambitious targets on waste treatment, renewable energy development, and water recycling, and all these are all policies that will ultimately lead to the transition towards a CE. Saudi Arabia Vision 2030 also captures the environment by increasing the efficiency of waste management, establishing comprehensive recycling projects, and reducing all forms [50].

\section{Achieving a CE Through Sustainable Energy and Water Consumption in Qatar}

The $\mathrm{CE}$ as a concept, as mentioned earlier, seeks to counter the traditional take-make-dispose linear economy to maximise products, components, and materials at all times. According to Ellen MarcArthur Foundation [44], the CE model is supported by a transition to renewable energy sources and helps economic, natural, and social capital. Jacobi et al.'s [51] findings show a strong connection between the $\mathrm{CE}$ and energy use and that the CE practices can consequently contribute to climate change mitigation. Urbanisation drives resource consumption and urban sustainability, by its nature, plays a role in achieving CE as it provides a balance between the trio of environment, economy, and society [52, 53]. There is also an increasing consensus on the role of energy, water, and carbon dioxide nexus play in achieving urban sustainability [54, 55]. Kennedy et al. [56] describe urban metabolism as a potent tool that can be used to achieve $\mathrm{CE}$ as it provides the opportunity to optimise energy consumption and resource flows.

Qatar's accelerated industrial development has put the environment at risk as ecosystem services and biological diversity are threatened. Recognising this, the country put various policy interventions to curtail the unintended negative impacts of their development effort through regulation and legislation by targeting better eco-service management and conservation [23]. QNV 2030 and the Qatar National Development Strategies 2011-2016 and 20182022 set objectives geared towards reducing the energy intensity of electricity consumption through awareness campaigns, standardisation, and seasonal shutdowns. According to the strategy, there is a need to improve thermal generation efficiency, adopt efficient technologies, and integrate renewable energy into the energy mix. The Second National Development Strategy (NDS-2) 2018-2022 is aligned with the SDGs. The industrial sector is not left out as ExxonMobil-Qatar Petroleum initiated a project to conduct a thorough review of RasGas LNG trains and Al Khaleej Gas plants. This was to monitor plant performance to see if there are plant and energy efficiency opportunities for energy conservation [57]. The Centre for Sustainable Energy Efficiency (CSEE) at Qatar Science and Technology Park was launched in 2011 by Chevron to support Qatar in achieving a sustainable development strategy [57]. In collaboration with the T.C. Chan Centre at the University of Pennsylvania in the USA, the Gulf Organization for Research and Development developed the Qatar Sustainability Assessment System (QSAS) [58, 59]. QSAS originated green building rating, which has the highest 
share in water efficiency (48\%), energy (72\%), sustainable site $(51 \%)$, IEQ (42\%), and operational management (24\%). The QSAS initiatives have addressed the local sustainability aspects of green building design criteria and develop site-specific building energy performance indicators. The NDS also targeted change of attitudes towards energy conservation. The strategy aims to imbibe energy conservation practices in commercial buildings and encourage owners to be more conscious of sustainability concerns (NDS 2011-2016). In 2012 Kahramaa launched a 5-year National Conservation Campaign (Tarsheed) under the banner "Keep Qatar Pulsing, Consume Wisely". The campaign hinges on the drive to preserving the environment and natural resources through three main objectives; (1) increasing the efficiency in the electricity and water sectors, (2) stopping waste and mindless consumption, and (3) reducing the consumption of electricity by $20 \%$ and water by $35 \%$ over the 5 -year period [58].

The discussion above identifies the policy landscape in sustainable energy use in Qatar. It provides a broad foundation for a possible CE policy approach in Qatar, but more needs to be done to achieve $\mathrm{CE}$ transition. In the case of energy sustainability in a $\mathrm{CE}$, policies must target principles that allow resources to be optimised, regenerated, virtualised, exchanged, shared, and closed loops prioritised [59]. Energy consumption is dominated by electricity and transportation, and thus, policies should reinforce the need to gain efficiencies and closed loops in these sectors. Electricity can be regenerated from waste; inner loops should be prioritised, such as renewable energy, especially in Qatar, where the sun is abundant. According to Tomić and Schneider [60], the "closing the loop" approach can be adopted in the case of energy sustainability in CE. Equipment and gadgets should continuously be replaced with more energy-efficient and durable ones. Also, there have to be more virtual space opportunities to allow people to work flexibly outside offices to conserve energy. When there is a shift away from owning vehicles to moving people, it will help efficient mobility. This will also mean building an efficient public transport network with most trips becoming multi-modal. These changes would lead to fewer and better-utilised cars. The positive side effects will include less congestion, less land and investment committed to parking and roads, and less air pollution due to less petroleum consumption. In this system, the cost per average passenger-km could drop by as much as $80 \%$ by 2050 [59]. Qatar's recent opening of the railway sector to the public is significant as this creates an opportunity to reduce the number of vehicles on the streets. Also, electric cars have good prospects of reducing carbon emissions, and switching to them will reduce environmental pollution.

With water supply, Qatar is doing well by recycling close to $100 \%$ of the water used. What is needed is to further optimise water usage by looking at water losses in transmission and recycled water reuse. Despite the high wastewater treatment in the GCC, only $15 \%$ is reused efficiently [61]. There is a need for a shift in water management thinking to achieve $\mathrm{CE}$ outcomes, taking cognisance of the internal and external factors underpinning this transition [62]. Internal factors include increasing value addition in the water production process. External factors involve using incentives to curb water pollution and creating awareness of the transition process from linear to CE. Again, the recycling system should move towards a decentralised system based on segregation at a source commonly used in developing countries as it is more complementing in achieving CE [63].

Qatar's arid climatic condition coupled with the benefit of a decentralised recycling system of wastewater makes constructed wetland technology adoption feasible. Stefanakis [64] concludes that the green technology of constructed wetlands $(\mathrm{CW})$ provides an ideal sustainable wastewater treatment solution under hot and arid climates. Constructed wetlands ecosystem functions are based on the coexistence of natural materials such as plants, wastewater, 
microorganisms, and biological processes stimulated by the system components' interactions [65]. The CW technology will provide an opportunity to exploit further non-conventional water resources, which can serve as a freshwater source in Qatar's water balance [64]. The CW development will provide a complementing role in transitioning to a CE in Qatar.

The agriculture sector is one of the industries that have to be considered regarding water use efficiency to achieve CE in Qatar. The agriculture sector is the highest water-consuming sector in Qatar. The water use per productivity in the industry has not seen a significant improvement over the years. Wastewater use in the industry needs improvement as when waste is adequately disaggregated, and chemicals can be extracted, which serve as nutrients for soil for improved yield. This was reported by a field study by [66], which investigated the status of wastewater treatment and agricultural reuse with particular reference to the Indian experience. Despite the benefit of using nutrients from wastewater for crop irrigation, Qatar's social standards are not accepted for usage [67]. To accelerate the transition to a $\mathrm{CE}$, the agriculture sector has to pursue regeneration, exchange, and optimise through innovative technologies. There is a need for more innovation in determining the exact water needed by plants to minimise wastage in planting crops. This will require better irrigation technologies and seedlings studies. The contribution of electricity, mobility, water supply, and agriculture, as discussed above, is presented in Fig. 3.

\section{Discussions}

Mannan et al. [12] conclude that thermal energy use in water desalination contributes to Qatar's highest adverse environmental impacts. The analysis shows that human toxicity is impacted the highest and followed by climate change, fossil depletion, marine eutrophication, and ozone depletion. The QNV2030 envisioned Qatar dealing with diminishing water

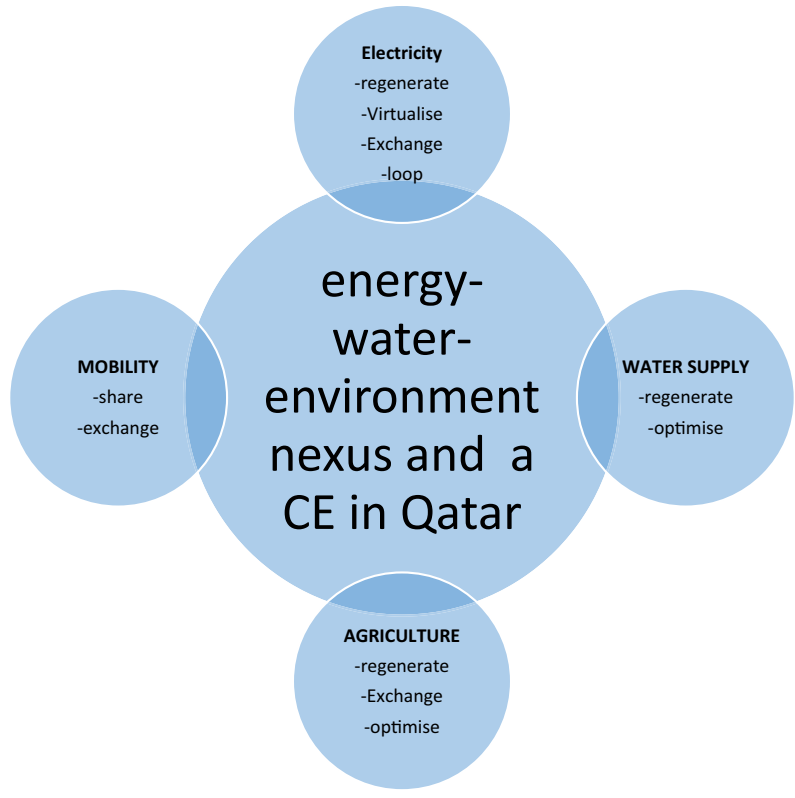

Fig. 3 Energy and water use in a CE in the case of Qatar 
resources and protecting the natural balance of water, air, land, and biological diversity. QNV2030 is the National Vision of Qatar that "defines broad future trends and reflects the Qatari people's aspirations, objectives, and culture". The vision "aims at transforming Qatar into an advanced country by 2030, capable of sustaining its development and providing for a high standard of living for all of its people for generations to come." Achieving this vision is anchored on four broad pillars of human development, social development, economic development, and environmental development. The implementation of the strategies under the QNV2030 has seen the rationalisation of energy and water consumption. This has reduced electricity per capita consumption by $18 \%$ and water per capita consumption by about $20 \%$ between 2012 and 2016 [68].

Qatar's natural gas supply contributes to the global supply of clean energy as natural gas is more efficient than crude oil and coal. Gas flaring has been a significant source of Qatar's carbon emission as it emits the highest in per capita terms in the world [69]. The country has embarked on a policy shift to reduce gas flaring by 50\% from 2008 to 2016 and thus decrease $\mathrm{CO} 2$ emissions as energy efficiency enhances [70]. The country joined the World Bank's Global Gas Flaring Reduction program as the first GCC country to take part [23]. Qatar can influence global energy sustainability standards in industrial symbiosis, which is concerned with maximising resources in an area where multiple industries are co-located [23]. This is possible by leveraging on its strong and developed natural gas market-a pioneering step in designing an industrial symbiosis model to enforce standards that promote technological advances. Faced with strict chlorine emission standards and the need to protect production integrity adequately, Qatar Gas embarked on a multi-year research program. The final result implemented the pulse-chlorination system designed explicitly for the biofouling conditions in Qatar [71]. This has seen a significant decrease in chlorine use and is considered the best available technology for seawater cooling systems [23].

Additionally, Qatar has embarked on energy pricing reform, which is pursued to rationalise energy consumption and drive towards energy efficiency from the demand side. Subsidies on petroleum products and electricity are slowly phased out. On the supply side, the government has intensified vetting of the cost structure of independent power producers to ensure that operational inefficiencies and wastage are not passed to consumers. This is done through the implementation of the efficiency-based economic operation by Kahramaa as of 2016 and standardising gas tariffs for production plants [72]. These policies are transformational, but the metrics for measuring impact remain unknown, and policymakers need to develop indicators to measure these policies' success. Also, Qatar Foundation has pioneered the green building initiative, which has seen solar energy as the source of electricity for buildings. There has also been some effort at converting waste to energy as solid waste is recycled into electrical power of 153 thousand MW and 39 tons of organic fertiliser [73].

Apart from reducing water consumption per capita, water loss in the desalination process has reduced from $30 \%$ in 2011 to $10 \%$ in 2016 (of which $4.7 \%$ was due to real loss and less than $6 \%$ was due to administrative loss) [68]. The improved water use efficiency in all sectors of the Qatari economy excludes the agricultural sector. The agricultural industry has seen a marginal decrease from 562 litres per GDP in 1990 to 534 litres per GDP in 2014, but this is less than those experienced in other sectors [74]. The synergies that may be gained from the energy-water-environment nexus can play a mitigating role in climate change effects in the future [75]. This is because energy and water are intertwined and interdependent valuable resources that drive economic growth and human well-being. The link between energy, water, and the environment is that when energy and water are not produced or used efficiently, it 
causes environmental problems through carbon emissions and unsanitary conditions [75]. The $\mathrm{CE}$ approach will require a concerted effort from multiple stakeholders, including government, industry, and community. Policymakers have a critical role in designing appropriate incentives and access to financing that promote the reuse of material and higher resource efficiency [76].

As Qatar prepares to launch the Qatar Water Strategy to operationalise the Qatar Water Policy, it will be instructive to consider the optimal use of water resources, including treated water reuse, to advance the CE's transition. The second NDS 2018-2022 aims to use 70\% of treated water, and $\mathrm{CW}$ technology can provide a useful tool for achieving this. Figure 4 presents the advantages and challenges of this technology in the case of Qatar.

Stefanakis et al. [77] assert that authorities in the Middle East focus mainly on the upfront investment in wastewater management decisions without intently considering the maintenance and operation costs in the long run, especially for conventional mechanical treatment technologies. Addressing the operational cost issue and the response to small and medium communities' wastewater treatment needs in Qatar essentialise the CW technology use. Also, the climatic condition in Qatar provides a perfect fit for CW technology. Despite these advantages, water loss issues, plant management, and social and cultural issues remain the challenges that need to be addressed in formulating and implementing a CW project in Qatar.

Apart from the specific sector approaches towards achieving CE within the energy-waterenvironment nexus, there has to be an overarching policy targeting sustainable consumption, sustainable production, sustainable environment awareness, research, and innovation [78]. Appropriate price signals of products and services should be used to incentivise behavioural change towards sustainable consumption. Market and policy incentives to reward efficiency should be encouraged, and companies should measure and benchmark lifecycle resource efficiency. A conscious educational and public campaign to alter attitudes towards embracing environmental conservation should be advanced.

CE transition success depends largely; the acceptability of the concept by local people and culture plays an important role. The study by Camacho-Otero et al. [79] concludes that culture remains a significant barrier in adopting CE practices such as "circular" business models and a

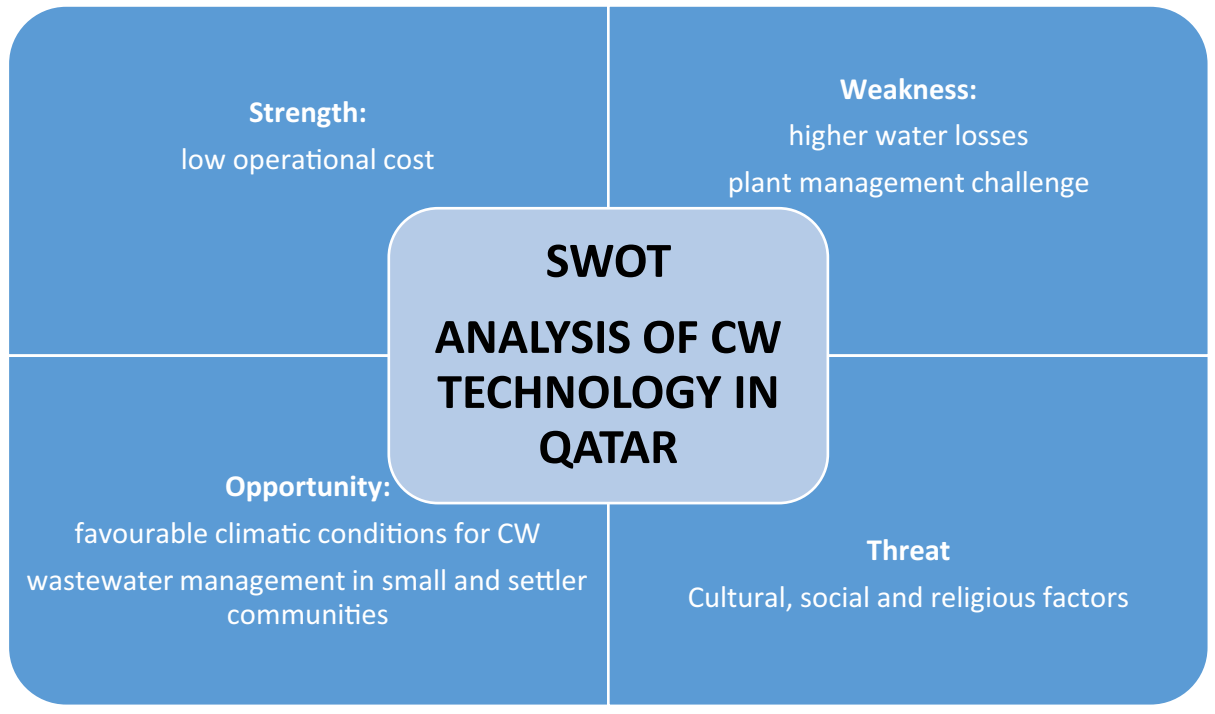

Fig. 4 SWOT analysis of constructed wetland technology implementation in Qatar (Source: adapted from [64]) 
general lack of consumer acceptance. This shows that for $\mathrm{CE}$ to see greater societal acceptance, cultural acceptance must be worked on. This will require policymakers' research to gauge citizens' understanding and behaviour towards CE. Behavioural and experimental economics tools may be adopted to help design incentives towards CE adaptation using nudges as this has been used as a policy tool in some studies, such as [80] in healthcare management, [81] on climate change, and [82] on energy conservation. [83] findings from a national survey in Qatar reveal that Qatar's residents highly accept greywater reuse depending on how people are introduced to greywater benefits. The greywater reuse framing as a cost-saving or water conservation measure generates the highest acceptance in the Qatari population.

It is essential to mention that the transition towards a $\mathrm{CE}$ is not a comfortable ride as some nuances must be considered. For instance, even though recycling is preferred to virgin production, it comes with high energy input [84]. This high energy consumption will possibly lead to high carbon footprints and so with large scale recycling. Authorities must also look at the energy intensity of the recycling technology. If this is neglected, a recycling-based CE's environmental benefits may be offset partially or entirely by the increased carbon emissions from energy use [85].

Further, many modern wastewater treatment plants require high levels of energy for pumping and aeration and resource consumption to transport and treat wastewater [86, 87]. Some municipal assemblies in the USA spend about 35\% of their energy budget on water and wastewater treatment facilities [87]. In European Union countries, drinking water and wastewater treatments account for $7.6 \%$ of the overall energy consumption [88]. The difference in energy consumption levels between the USA and Europe shows an opportunity for energy savings with appropriate policies. This presents a research opportunity to gain a more systematic understanding of the trade-offs between materials, energy, and emissions involved in substantially improving recycling [51].

\section{Conclusion and Policy Recommendations}

To formulate CE policies to achieve growth within existing resources, the nexus between energy, water, and the environment presents an essential perspective for policymakers. This study explores the energy-water-environment nexus in Qatar and how to leverage it to transition the country towards a CE and sustainable development as a whole. The nexus between energy, water, and the environment provides a valuable policy tool that can be used to quicken the transition towards CE. Energy and water production and consumption have adverse effects on the environment, and CE provides an opportunity to mitigate environmental consequences and achieve sustainable development by reusing, reducing, and recycling resources to increase lifespan and gain efficiency. Qatar has carried out numerous initiatives with guidance from the QNV2030. Pillar 3 (economic development) and pillar 4 (environmental development) set targets towards achieving CE. The success assessment remains unclear, partly due to a lack of CE policy framework and criteria for assessing outcomes. The electricity and mobility sectors(energy perspective of the $\mathrm{CE}$ ) and agriculture and water supply system (water perspective of the CE) of the Qatari economy provide an opportunity for regeneration, virtualising, exchanging, optimising, sharing, and closing the loops to achieve $\mathrm{CE}$ growth. The nexus between the mobility, electricity, agriculture, and water supply system needs consideration for optimal policy outcome for the CE in Qatar. 
To transition to a CE in Qatar, the following may be considered by policymakers:

1. Policymakers in Qatar have to consider mobility, electricity, agriculture, and water supply system sectors' nexus in developing the CE policy framework to accelerate the transition.

2. Policymakers should provide the framework to support public sector institutions, private businesses, and household incentives to pursue CE practices in the electricity, transport, agriculture, and water supply systems. The policies must motivate and equip them to virtualise, optimise, regenerate, share, exchange, and close the loop to achieve CE in Qatar.

3. There is a need to embark on public awareness on $\mathrm{CE}$ education, emphasising moving away from make, use, and dispose to make, reduce, reuse, and recycle.

4. There is a need for attitudinal change towards resource efficiency, and policymakers may have to undertake behavioural studies towards nudging social behaviour towards CE adoption.

5. There has to be a comprehensive CE policy that consolidates the QNV2030 and NDS 2018-2022 to provide policy clarity and communication towards the CE transition with measurable indicators of success. The QSAS success offers a springboard for CE policy development.

6. Qatar Water Policy strategy should consider integrating nature-based solutions and smart reuse and recycling of treated wastewater by considering CW's implementation in Qatar to maximise recycled wastewater usage.

Author Contribution All authors contributed to the study conception and design. Material preparation, data collection, and analysis were performed by Abdul-Jalil Ibrahim. Abdul-Jalil Ibrahim wrote the first draft of the manuscript and Nasim S. Shirazi commented and improved on previous versions of the document. All authors read and approved the final manuscript.

Funding Open access funding provided by the Qatar National Library.

\section{Declarations}

Consent for Publication Authors give consent for the manuscript to be published. Authors are responsible for the correctness of the statements provided in the manuscript

Conflict of Interest The authors declare no competing interest.

Open Access This article is licensed under a Creative Commons Attribution 4.0 International License, which permits use, sharing, adaptation, distribution and reproduction in any medium or format, as long as you give appropriate credit to the original author(s) and the source, provide a link to the Creative Commons licence, and indicate if changes were made. The images or other third party material in this article are included in the article's Creative Commons licence, unless indicated otherwise in a credit line to the material. If material is not included in the article's Creative Commons licence and your intended use is not permitted by statutory regulation or exceeds the permitted use, you will need to obtain permission directly from the copyright holder. To view a copy of this licence, visit http://creativecommons.org/licenses/by/4.0/.

\section{References}

1. Tsolas SD, Karim MN, Hasan MF (2018) Optimisation of water-energy nexus: a network representationbased graphical approach. Appl Energy 224:230-250 
2. Shannon MA, Bohn PW, Elimelech M, Georgiadis JG, Marinas BJ, \& Mayes AM (2010) Science and technology for water purification in the coming decades. In Nanoscience and technology: a collection of reviews from nature Journals (pp. 337-346).

3. Birol F. World energy outlook (2010). Int Energy Agency 2010

4. United Nations (2014) Water and Energy. World Water Day 2014

5. Adham S, Hussain A, Matar JM, Dores R, Janson A (2013) Application of membrane distillation for desalting brines from thermal desalination plants. Desalination 314:101-108

6. Zak GM, Ghobeity A, Sharqawy MH, Mitsos A (2013) A review of hybrid desalination systems for coproduction of power and water: analyses, methods, and considerations. Desalin Water Treat 51(28-30): 5381-5401

7. Rothausen SG, Conway D (2011) Greenhouse-gas emissions from energy use in the water sector. Nat Clim Chang 1(4):210-219

8. Howells M, Rogner HH (2014) Water-energy nexus: assessing integrated systems. Nat Clim Chang 4(4): 246-247

9. Hofste RW, Reig P, and Schleifer L( 2019) 17 Countries, home to one-quarter of the world's population, face extremely high water stress. World Resource Institute accessed on 120/2/2021 at https://www.wri.org/ blog/2019/08/17-countries-home-one-quarter-world-population-face-extremely-high-water-stress

10. Darwish MA, Mohtar R (2013) Qatar water challenges. Desalin Water Treat 51(1-3):75-86

11. Sadik AK (2013) Agriculture, water and food security in GCC countries. Sixth Zayed Seminar 8 - 9 May 2013 Arabian Gulf University, Manama

12. Mannan M, Alhaj M, Mabrouk AN, Al-Ghamdi SG (2019) Examining the lifecycle environmental impacts of desalination: a case study in the State of Qatar. Desalination 452:238-246

13. PSA(2019 and 2017).Qatar Water Statistics. https://www.psa.gov.qa/en/statistics/Statistical\%20Releases/ Environmental/Water/2017/Water-Statistics-2017-EN.pdf. https://www.psa.gov.qa/en/statistics/Statistical\% 20Releases/Environmental/Water/2019/Water_infographic_2019_EN.pdf

14. Ismail H (2015) Food and water security in Qatar: Part 2-W̄ater Resources. Future Directions International Pty Ltd. Dalkeith WA, Australia

15. Baalousha HM, Ouda OK (2017) Domestic water demand challenges in Qatar. Arab J Geosci 10(24):537

16. Lanouar C, Al-Malk AY, Al Karbi K (2016) Air pollution in Qatar: causes and challenges. College of Business and Economics, Qatar University 1:1-7

17. World Bank (2018) World Development Indicators (WDI). Accessed on 4/12/2019 from: https://databank. worldbank.org/source/world-development-indicators\#

18. Kaharaama (2016) Annual Statistics Report https://www.km.com.qa/MediaCenter/Publications/ Landscape\%20A4\%20Size-English.pdf

19. Del Borghi A, Moreschi L, Gallo M (2020) Circular economy approach to reduce water-energy-food nexus. Curr Opin Environ Sci Health 13:23-28

20. International Water Association Report(2017). Accessed on 4/3/2020 at https://iwa-network.org/ publications/iwa-annual-report-2017-2018/

21. Ellen McArthur Foundation(2016). The new plastics economy: rethinking the future of plastics accessed on 4/12/2019 at https://www.ellenmacarthurfoundation.org/publications/the-new-plastics-economy-rethinkingthe-future-of-plastics

22. Ellen Macarthur Foundation(2017) Achieving "growth within" accessed on 5/12/2020 at https://www. ellenmacarthurfoundation.org/publications/achieving-growth-within

23. Richer R (2009) Conservation in Qatar: impacts of increasing industrialization. Doha, Qatar: Center for International and Regional Studies. Occasional Paper (2).

24. Ansuategi A, Escapa M (2002) Economic growth and greenhouse gas emissions. Ecol Econ 40(1):23-37

25. López-Menéndez AJ, Pérez R, Moreno B (2014) Environmental costs and renewable energy: re-visiting the Environmental Kuznets Curve. J Environ Manag 145:368-373

26. Qatar Petroleum (2019) H.E. Al-Kaabi: Qatar will be capturing and sequestering more than 5 million tons per annum of CO2 by 2025 accessed on 2/12/2019 at https://qp.com.qa/en/Pages/BannerAdvertisement. aspx ?imgname $=08102019+\mathrm{HE}+\mathrm{CEO}+-+\mathrm{Oil}+$ and+Money+Conference+2019+English.jpg

27. Tan C, Zhi Q (2016) The energy-water nexus: a literature review of the dependence of energy on water. Energy Procedia 88:277-284

28. Ellen Macarthur Foundation (2015). Growth within: a circular economy vision for a competitive Europe. Accessed on 12/12/2019 at https://www.ellenmacarthurfoundation.org/publications/growth-within-acircular-economy-vision-for-a-competitive-europe

29. Ellen Macarthur Foundation (2012). Towards the circular economy vol. 1: an economic and business rationale for an accelerated transition. Accessed on 12/12/2019 at https://www.ellenmacarthurfoundation. org/publications/towards-the-circular-economy-vol-1-an-economic-and-business-rationale-for-anaccelerated-transition 
30. European Commission (2015). Closing the loop - an EU action plan for the Circular Economy. Accessed on 12/12/2019 at https://eur-lex.europa.eu/resource.html?uri=cellar:8a8ef5e8-99a0-11e5-b3b7-01aa75ed71a1. 0012.02/DOC 1\&format=PDF

31. Frosch D, Gallopoulos N (1989) Strategies for manufacturing. Sci Am 261(3):94e102

32. Ellen Macarthur Foundation (2013). Towards the circular economy vol. 2: opportunities for the consumer goods sector. Accessed on 12/12/2019 at https:/www.ellenmacarthurfoundation.org/publications/towardsthe-circular-economy-vol-2-opportunities-for-the-consumer-goods-sector

33. Geissdoerfer M, Savaget P, Bocken NM, Hultink EJ (2017) The circular economy-a new sustainability paradigm? J Clean Prod 143:757-768

34. Rashid A, Asif FM, Krajnik P, Nicolescu CM (2013) Resource conservative manufacturing: an essential change in business and technology paradigm for sustainable manufacturing. J Clean Prod 57:166-177

35. Mihelcic JR, Crittenden JC, Small MJ, Shonnard DR, Hokanson DR, Zhang Q, Chen H, Sorby SA, James VU, Sutherland JW, Schnoor JL (2003) Sustainability science and engineering: the emergence of a new metadiscipline. Environ Sci Technol 37(23):5314-5324

36. Braungart M, Mcdonough W, Bollinger A (2007) Cradle-to-cradle design: creating healthy emissions e a strategy for eco-effective product and system design. J Clean Prod 15(13e14):1337e1348

37. European Commission (2018). Circular economy action plan: for a cleaner and more competitive Europe. Accessed on 12/12/2019 at https:/ec.europa.eu/environment/circular-economy/pdf/new_circular_ economy_action_plan.pdf

38. Domenech T, Bahn-Walkowiak B (2019) Transition towards a resource efficient CE in Europe: policy lessons from the EU and the member states. Ecol Econ 155:7-19

39. European Commission (2014) Towards a circular economy: a zero waste programme for Europe. Accessed on 12/ 12/2019 at https://ec.europa.eu/environment/circular-economy/pdf/circular-economy-communication.pdf

40. House of Commons Environmental Audit Committee, "Growing a circular economy: ending the throwaway society," accessed July 17, 2014, http:// www.publications.parliament.uk/pa/cm201415/cmselect/ cmenvaud/214/214.pdf

41. Sanderson P (2014) Government rejects MPs recommendations on economy. Resource efficient business.

42. Lacy P, Rutqvist J (2016) Waste to wealth: The CE advantage. Springer

43. Zhu D (2014) China's policies a The Circular Economy Opportunity for Urban and Industrial Innovation in China nd instruments for developing the CE. Europe's world.

44. EllenMarcArthur Foundation(2018) Accessed on 12/12/2019 at https://www.ellenmacarthurfoundation.org/ publications/chinareport

45. Ministry of the Environment Japan (2000) Law for the Promotion of Effective Utilisation of Resources. Japan, Government of

46. Stephanie Cairns and Meg Ogden, with Scott McFatridge. (2018). Getting to a CE: a primer for Canadian policymakers. Policy Brief.

47. Tanaka I (2014). Promotion of resource efficiency in japan. Swedish Institute for growth policy studies. Accessed on 16/03/2019 https://www.tillvaxtanalys.se/download/18.1af15a1f152a3475a819a2a/ 1454513350623/Promotion+of+Resource+Efficiency+in+Japan-08.pdf

48. World Government Summit(2019). Putting GCC cities in the loop: sustainable growth in a circular economy . Accessed on 12/12/2019 https:/www.worldgovernmentsummit.org/observer/reports/2019/ detail/putting-gcc-cities-in-the-loop-sustainable-growth-in-a-circular-economy

49. Qatar National Vision 2030 (2008) accessed on 1/11/2019 at https://www.psa.gov.qa/en/qnv1/Pages/ default.aspx

50. Abdulwahab Al-Sadoun(2019)From waste to value: the GCC chemical industry's contribution to CE accessed on 14/03/19 at https:/gpca.org.ae/2019/03/05/from-waste-to-value-the-gcc-chemical-industryscontribution-to-circular-economy/. accessed 15 October 2018)

51. Jacobi N, Haas W, Wiedenhofer D, Mayer A (2018) Providing an economy-wide monitoring framework for the CE in Austria: status quo and challenges. Resour Conserv Recycl 137:156-166

52. Daly HE (1995) On Wilfred Beckerman's critique of sustainable development. Environ Values 4:49-55

53. Wu JG (2013) Landscape sustainability science: ecosystem services and human wellbeing in changing landscapes. Landsc Ecol 28(6):999-1023

54. Childers DL, Pickett ST, Grove JM, Ogden L, Whitmer A (2014) Advancing urban sustainability theory and action: challenges and opportunities. Landsc Urban Plan 125:320-328

55. Huang L, Wu J, Yan L (2015) Defining and measuring urban sustainability: a review of indicators. Landsc Ecol 30(7):1175-1193

56. Kennedy C, Cuddihy J, Engel-Yan J (2007) The changing metabolism of cities. J Ind Ecol 11(2):43-59

57. Meltzer J, Hultman NE, Langley C (2014) Low-carbon energy transitions in Qatar and the Gulf cooperation council region. Brook Pap Econ Act 
58. Sharifi A, Murayama A (2013) A critical review of seven selected neighborhood sustainability assessment tools. Environ Impact Assess Rev 38:73-87

59. GORD (2010) Qatar Sustainability Assessment System (QSAS), Gulf Organization for Research and Development. Doha, Qatar

60. Tomić T, Schneider DR (2018) The role of energy from waste in CE and closing the loop concept-energy analysis approach. Renew Sust Energ Rev 98:268-287

61. United Nations World Water Assessment Programme(2017). Wastewater: the untapped resource. In The United Nations World Water Development Report 2017; UNESCO: Paris, France, 2017.

62. Flores CC, Bressers H, Gutierrez C, de Boer C (2018) Towards CE - a wastewater treatment perspective, the Presa Guadalupe case. Manag Res Rev 41(5):554-571

63. Krishnakumar B, Majumdar S, Manilal VB, Haridas A (2005) Treatment of sulphide containing wastewater with sulphur recovery in a novel reverse fluidised loop reactor (RFLR). Water Res 39:639-647

64. Stefanakis AI (2020) Constructed wetlands for sustainable wastewater treatment in hot and arid climates: opportunities, challenges and case studies in the Middle East. Water 12(6):1665

65. Stefanakis, A.I. (2015). Constructed wetlands: description and benefits of an eco-tech water treatment system. In Impact of Water Pollution on Human Health and Environmental Sustainability, 1st ed.; McKeown, A.E., Bugyi, G., Eds.; Information Science Reference (an imprint of IGI Global): Hershey, Derry Township, PA, USA, pp. 281-303.

66. Shende $G B(1985)$ Status of wastewater treatment and agricultural reuse with special reference to Indian experience and research and development needs. In Proceedings of the FAO Regional Seminar on the Treatment and Use of Sewage Effluent for Irrigation, Nicosia, Cyprus, 7-9 October 1985; Pescod, M.S., Arar, A., Eds.; Butterworths: London, UK.pp. 185-209

67. Darwish M, Abdulrahim H, Nasser Mabrouk A, Hassan A, Shomar B (2015) Reclaimed wastewater for agriculture irrigation in Qatar. Glob J Agric Res Rev 3:106-120

68. SDGs Qatar Voluntary National Review (2018). Accessed on 1/12/2019 at https://sustainabledevelopment. un.org/memberstates/qatar

69. United Nation Development Program. Expanding the Capacities of Qatari Youth; Mainstreaming Young People in Development. 2012. http:/www.youthpolicy.org/library/documents/qatars-third-national-humandevelopmentreport-expanding-the-capacities-of-qatari-youth-mainstreaming-young-people-indevelopment/. Accessed March 5, 2019

70. Ayoub N, Musharavati F, Pokharel S, Gabbar HA (2014) Energy consumption and conservation practices in Qatar - a case study of a hotel building. Energy and Buildings 84:55-69

71. Macdonald IA, Polman HJ, Jenner HA, Quyam SQ (2012) Pulse-chlorinationw: Anti-fouling optimisation in seawater cooling systems. In: Rajagopal S, Jenner HA, Venugopalan VP (eds) Operational and environmental consequences of large industrial cooling water systems. Springer, New York, US, pp 287-301

72. SDGs Qatar Voluntary National Review (2017) accessed on 1/12/2019 at ](SDGs Qatar Voluntary National Review, 2017

73. Ministry of Development Planning and Statistics (2017). Accessed on 5/12/2020 at https://www.psa.gov.qa/ en/knowledge1/Publications/Pages/Sustainable.aspx

74. Planning and Statistics Authority (2017) Qatar Water Statistics. accessed on 1/12/2020 at https://www.psa. gov.qa/en/statistics/Statistical\%20Releases/Environmental/Water/2017/Water-Statistics-2017-EN.pdf

75. Shahzad MW, Burhan M, Ang L, Ng KC (2017) Energy-water-environment nexus underpinning future desalination sustainability. Desalination 413:52-64

76. Ellen Macarthur Foundation (2019) Circular economy in cities. Accessed on 1/12/2019 at https://www. ellenmacarthurfoundation.org/publications/circular-economy-in-cities-project-guide

77. Stefanakis AI, Akratos CS, Tsihrintzis VA (2014) Modeling of Vertical Flow Constructed Wetlands. In: Vertical flow constructed wetlands: eco-engineering systems for wastewater and sludge treatment, $1 \mathrm{st}$ edn. Elsevier Publishing, Amsterdam, The Netherlands

78. Domenech T, Bahn-Walkowiak B (2019) Transition towards a resource efficient CE in Europe: policy lessons from the EU and the member states. Ecol Econ 155:7-19

79. Camacho-Otero J, Boks C, Pettersen I (2018) Consumption in the CE: a literature review. Sustainability 10(8):2758

80. Voyer B (2015) 'Nudging' behaviours in healthcare: Insights from behavioural economics. Br J Healthc Manag 21(3):130-135

81. Gowdy JM (2008) Behavioral economics and climate change policy. J Econ Behav Organ 68(3-4):632-644

82. Khashe S, Heydarian A, Becerik-Gerber B, Wood W (2016) Exploring the effectiveness of social messages on promoting energy conservation behavior in buildings. Build Environ 102:83-94

83. Lambert LA, Lee J (2018) Nudging greywater acceptability in a Muslim country: comparisons of different greywater reuse framings in Qatar. Environ Sci Pol 89:93-99 
84. Allwood J, Konadu D, Mourao Z, Lupton R, Richards K, Fenner R,(2016) Integrated Analysis of landwater-energy assessment using the foreseer tool. In EGU General Assembly Conference Abstracts, vol. 18.p. 17130.

85. Liu L, Hejazi M, Patel P, Kyle P, Davies E, Zhou Y, Clarke L, Edmonds J (2015) Water demands for electricity generation in the US: modeling different scenarios for the water-energy nexus. Technol Forecast Soc Chang 94:318-334

86. Mihelcic JR, Crittenden JC, Small MJ, Shonnard DR, Hokanson DR, Zhang Q, Schnoor JL (2003) Sustainability science and engineering: the emergence of a new metadiscipline. Environ Sci Technol 37(23):5314-5324

87. Roccaro P, Sgroi M, Vagliasindi FG (2013) Removal of xenobiotic compounds from wastewater for environment protection: treatment processes and costs. Chem Eng Trans 32

88. EEA: Performance of water utilities beyond compliance (Technical report No. 5/ 2014). Luxembourg. 2014. 